DOI 10.37882/2223-2982.2020.04-2.21

\title{
ОСОБЕННОСТИ ДЕЯТЕЛЬНОСТИ ОБУЧАЮЩИХСЯ В МАЛЫХ ГРУППАХ СОТРУДНИЧЕСТВА НА СРЕДНЕМ ЭТАПЕ ОБУЧЕНИЯ ИНОСТРАННОМУ ЯЗЫКУ
}

\section{FEATURES OF STUDENTS ' ACTIVITIES IN SMALL GROUPS OF COOPERATION AT THE MIDDLE STAGE OF FOREIGN LANGUAGE TRAINING}

T. Kovaleva

A. Karaseva

Summary: The article is devoted to the features of the educational activities of students in small groups of cooperation at the middle stage of teaching a foreign language. The relevance of the use of group communication technologies in the educational activities of students in teaching a foreign language at the middle stage of education from the point of view of the age-psychological characteristics of adolescent students is substantiated. The essential characteristics of the group form of work in educational activity and its advantages are disclosed. Some examples of the use of technology of small groups of cooperation at the intermediate level of teaching students a foreign language are presented. It is concluded that training in small groups of cooperation is an effective condition for the development of students' foreign language communicative competence.

Keywords: training, foreign language, small groups, cooperation, middle stage of training.

\author{
Ковалева Татьяна Анатольевна \\ К.филол.н., доцент, ГОУВО МО «Государственный \\ социально-гуманитарный университет» \\ z-tatiana@yandex.ru \\ Карасева Арина Александровна \\ ГОУВО МО «Государственный \\ сочиально-гуманитарный университет»
}

Аннотация: Статья посвящена особенностям учебной деятельности обучающихся в малых группах сотрудничества на среднем этапе обучения иностранному языку. Обоснована актуальность применения групповых коммуникативных технологий в учебной деятельности учащихся при обучении иностранному языку на среднем этапе обучения с точки зрения возрастнопсихологических особенностей учащихся подросткового возраста. Раскрыты сущностные характеристики групповой формы работы в учебной деятельности и ее достоинства. Представлены некоторые примеры использования технологии малых групп сотрудничества на средней ступени обучения учащихся иностранному языку. Сделан вывод о том, что обучение в малых группах сотрудничества является эффективным условием развития иноязычной коммуникативной компетенции учащихся.

Ключевые слова: обучение, иностранный язык, малые группы, сотрудничество, средний этап обучения.

ростковом возрасте появляется новая деятельность - интимно-личностное общение со сверстниками, возникает «чувство взрослости» как особая форма самосознания, благодаря которой подросток сравнивает себя с другими и находит новые образцы для подражания [6]. Таким образом, на среднем этапе обучения в подростковом возрасте имеет место возрастающая значимость общения со сверстниками, что обуславливает актуальность применения групповых коммуникативных технологий в учебной деятельности учащихся, в частности применения малых групп сотрудничества при обучении иностранному языку.

Групповая форма обучения определяется как «способ организации совместной деятельности учащихся в малых группах при опосредованном руководстве и в сотрудничестве с учителем» [1, с. 27]. Суть групповой работы, по мнению автора, выражается в таких ее характеристиках, как, с одной стороны, наличие непосредственного взаимодействия между учащимися, с другой - опосредованном руководстве деятельностью учени- 
ка со стороны учителя, которое строится по принципу «учитель - группа сотрудничающих между собой учеников». Такие особенности групповой работы дают дополнительный эффект в развитии, воспитании и обучении учащихся. На эффективность групповой учебной деятельности учащихся указывала Г.А. Цукерман, согласно которой групповая работа учащихся является областью «детской полусамостоятельности», где помощь взрослого уже не нужна, а необходимой становится помощь сверстника. Достоинствами групповой формы работы является способность группы работать в своем темпе, отсутствие непосредственного контроля учителя, взаимопомощь учащихся [5].

Эффективность применения технологии малых групп сотрудничества показана в исследовании Е.Г. Ивановой на начальном этапе обучения иностранному языку. Автором представлена учебная деятельность учащихся в условиях групповой работы малых групп, состоящих из 3 человек («Вертушка»), и состоящих из 4 человек («Лидер»), целью которой являлось формирование лексико-грамматических навыков и развитие умений творческого применения речевого материала при обучении иностранному языку [3].

На средней ступени обучения в процессе изучения иностранного языка приоритетным является последовательное и систематичное развитие у учащихся всех составляющих иноязычной коммуникативной компетенции, включающей этапы обучения аудированию, чтению, говорению и письмо. В процессе обучения иностранному языку учебная деятельность учащихся носит цикличный характер и включает все перечисленные этапы, которые реализуются в каждой серии уроков [4, с. 257]. Использование технологии малых групп сотрудничества на уроках иностранного языка на средней ступени обучения, в отличие от начальной ступени, имеет более широкие возможности. Обучение в малых группах сотрудничества являются эффективным условием развития таких составляющих иноязычной коммуникативной компетенции учащихся, как чтение, предполагающее совместную работу учащихся с текстом; говорение, предполагающее обмен устной информацией в условиях группового коммуникативного взаимодействия в малой группе; письмо, предполагающее совместную работу учащихся над письменными текстами. Технология обучения в малых группах сотрудничества эффективна в учебных заданиях, целью которых является развитие речевой компетенции, учебно-познавательной компетенции, предполагающей формирование умений критического мышления, интеллектуальных и общеучебных умений, социокультурной компетенции, включающей овладение социокультурными знаниями и умениями. Возможно использование нескольких моделей обучения в сотрудничестве, выбор которых зависит от типа проблемного задания и дидактической задачи, на решение которой оно направлено [2].

Приведем некоторые примеры использования технологии малых групп сотрудничества на средней ступени обучения учащихся иностранному языку. С целью формирования грамматического навыка на тренировку употребления глаголов в Pesent Perfect и Past Simple учащиеся выполняют упражнения, в соответствии с инструкцией к которому, необходимо закончить предложения, указать время и условия происхождения действия. Учащиеся разбиваются на группы из 3-х человек, каждая из которых работает по модели «Вертушка», согласно которой каждое последующее задание выполняется следующим учеником.

В процессе работы учащихся с текстом, целью которой является анализ текста, совершенствование написанных сочинений, можно применить принцип «Jigsaw» посредством реализации групповой работы в форме игры «Соревнование издательств». С этой целью организуется работа группы, состоящей из 4-5 учащихся, которые получают следующие групповые роли: редактор (капитан, сильный ученик); корректор (учащийся, который берет на себя ответственность за соблюдение орфографии и пунктуации в исправленном тексте); рецензент (учащийся, который отвечает за отзыв на исправленный текст); каллиграф (слабый учащийся, который под контролем корректора должен переписать текст красиво и правильно). Групповая работа включает несколько этапов, каждый из которых подчинен собственным задачам. На первом этапе учащиеся распределяют роли и осуществляют первичное ознакомление с текстом в ходе коллективного обсуждения его недостатков. На втором этапе редактор вносит первоначальные правки с подробным их объяснением другим членам группы. Третий этап предполагает повторное чтение текста и устранение недостатков в употреблении слов и в построении предложений с использованием условных обозначений. Следующим этапом групповой работы учащихся является чтение текста вслух, что позволяет окончательно выявить все недостатки, после чего подводятся итоги, на основании которых осуществляется работа рецензентов. После этого в группе проводится обсуждение плана и содержания рецензии, далее оформление рецензии рецензентом, после чего каллиграфы под контролем редактора и корректора переписывают исправленный текст. Замечания по исправлению орфографических и пунктуационных ошибок может делать только корректор, а редактор должен следить за тем, чтобы были внесены все его правки. Заключительный этап представляет собой чтение окончательного варианта исправленного текста и рецензии. Учебная деятельность в групповой игровой форме позволяет учащимся приобрести опыт группового взаимодействия, умения высказывать свое мнение, отстаивать свою точку зрения, искать компромиссы. 
Итак, целесообразность использования технологии малых группах сотрудничества определяется, с одной стороны, ее дидактическими свойствами, с другой, целями и задачами обучения учащихся. Малые группы сотрудничества являются эффективным условием обучения иностранному языку учащихся среднего этапа об- учения при формировании лексических и грамматических навыков, при формировании интеллектуальных и речевых умений в разных видах учебной деятельности, включающей говорение, чтение, письмо, направленных на формирование основных компонентов иноязычной коммуникативной компетенции учащихся.

\section{ЛИТЕРАТУРА}

1. Витковская И.М. Обучение младших школьников в совместной деятельности. - Псков, 2000. - 96 с.

2. Джонсон Д., Джонсон Р., Джонсон-Холубек Э. Методы обучения. Обучение в сотрудничестве. - СПб.: Экономическая школа, 2001. - 256 с.

3. Иванова Е. Г. Методика обучения в сотрудничестве на начальном этапе средней общеобразовательной школы: диссертация кандидата педагогических наук. - Москва, 2013. - 210 с.

4. Методика обучения иностранным языкам в средней школе: Учебник / Н.И. Гез, М.В. Ляховицкий, А.А. Миролюбов и др. - М.: Высшая школа, 2017.- 373с.

5. Цукерман Г.А. Совместная учебная деятельность как основа формирования умения учиться: диссертация на соискание ученой степени доктора психологических наук. - Москва, 1992. - 343 с.

6. Эльконин Д.Б. Детская психология: учебное пособие для студентов вузов. - М.: Академия, 2011. - 384 с.

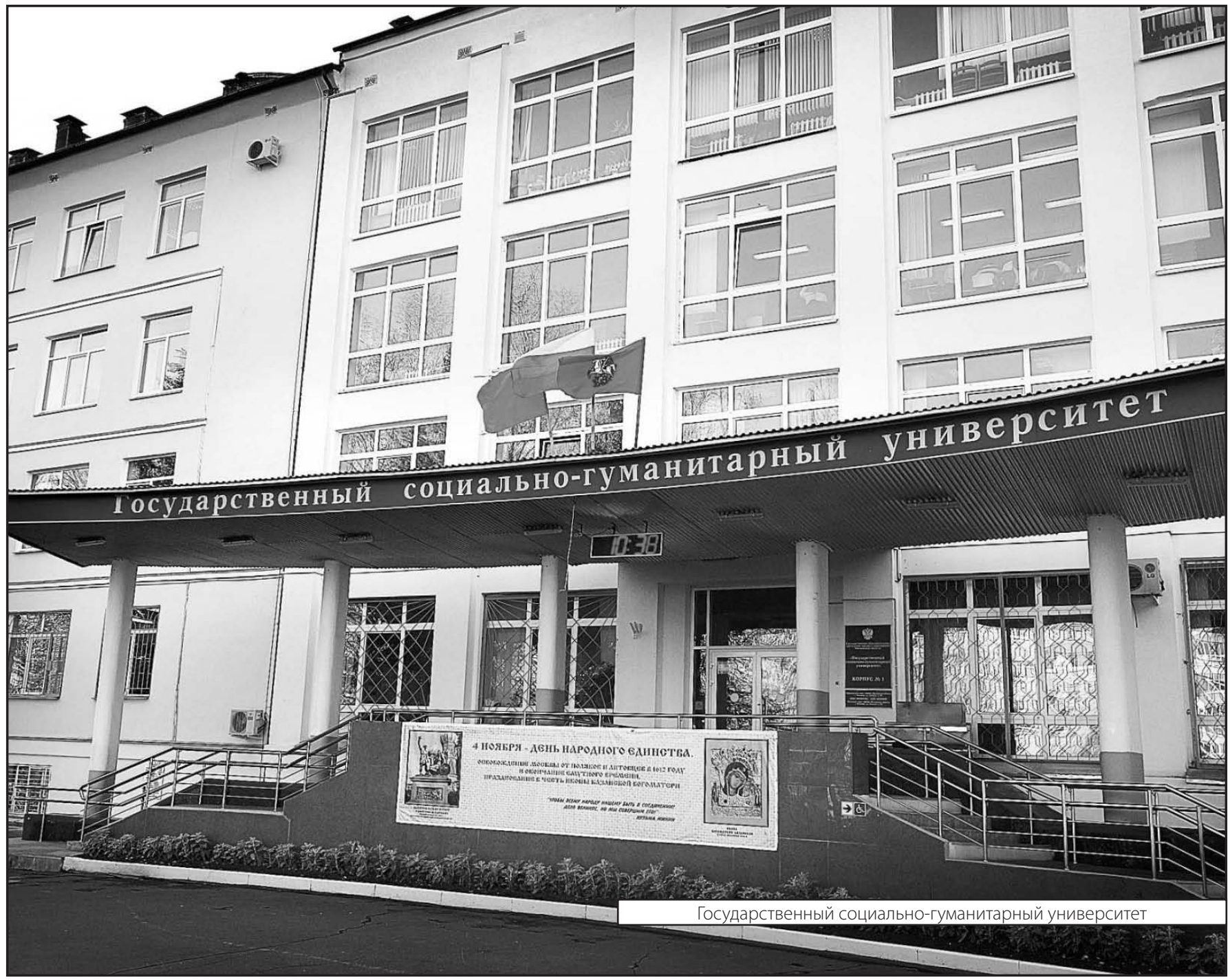

